Rev. Inst. Med. trop. São Paulo

31!6): 368-376, novembro-dezembro, 1989

\title{
Legionella pneumophila ASSOCIADA A INSUFICIÊNCIA RESPIRATÓRIA AGUDA. PRIMEIRO ISOLAMENTO NO BRASIL (1)
}

\section{RESUMO}

Relatam os autores isolamento de Legionella pneumophila sorogrupo 1, acom panhado de evidências sorológicas de infecção atual, em homem de 40 anos com infecção respiratória grave que evoluiu para insuficiencia respiratória aguda. Esta foi caracterizada por hipoxemia severa refratária a altas concentraçōes de oxigênio e radiograficamente por infiltrados difusos em ambos pulmóes. Com introdução de clindamicina, amicacina, ceftriaxone e ventilaçào à volume com Pressão Expira-

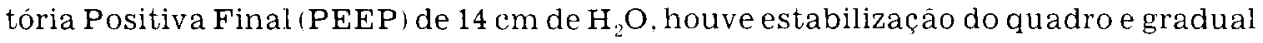
recuperaçào.

Suspeitando-se de legionelose, foi colhido sangue e secreçāo traqueal para exames específicos. A secreção traqueal foi semeada em meio BCYE com isolamento de bacilo gram-negativo, identificado como Legionella pneumophila sorogrupo 1 por características culturais, bioquímicas e reaçōes de imunofluorescencia direta e de aglutinaçāo em lámina. O estudo sorológico revelou títulos de anticorpos 128 , 1024, 4096 e 8192 para amostras coletadas na 1:, 3?, 4? e 6. semanas após o início do quadro. Os resultados definitivos foram obtidos com o paciente em recuperação.

É realçada a comprovação da presença de Legionella sp. como agente patológico em nosso meio; a importancia das medidas de suporte na evoluçāo do paciente: a necessidade de se pensar neste agente no diagnóstico diferencial de pneumonias e de se pesquisar mais esta etiologia com metodologia laboratorial específica.

UNITERMOS: Legionella pneumophila; Isolamento; Insuficiência respiratória aguda.

\section{INTRODUÇÃO}

As pneumopatias infecciosas representam sempre um desafio ao esclarecimento etiológico preciso, mesmo em se tratando de agentes bacterianos clássicos. Formas atípicas podem ser de

\footnotetext{
(1) O caso clinico deste trabalho foi apresentado no XXIV Congresso Brasileiro de Pneumologia e Tisiologia, realizado de 7 a 10 de setembro de 1988 em Curitiba, Paraná, Brasil.

(2) Medico Assistente da Divisào de Clinica Medica do Hospital das Clínicas da Faculdade de Medicina da Universidade de Sào Paulo (FMUSP). Sảo Paulo, SP. Brasil

(3) Farmaceutica Bioquimica - Laboratório de Investigaçào Médica LIM/54 - HC FMUSP. Sảo Paulo, SP, Brasil.

4) Prof Resp. Disc. Patol. Clínica - Departamento de Patologia da FMUSP - LIM/54 e Instituto de Medicina Tropical de Sảo Paulo. Sāo Paulo, SP, Brasil.

(5) Prof. Titular da Diseiplina de Clínica Geral e Propedêtica da FMUSP. Sảo Paulo, SP, Brasil.

Endereço para correspondêneia: Prof. Dr. Cid Vieira Franco de Godoy. Instituto de Medicina Tropical de Sảo Paulo. Av. Dr Enéas de Carvalho Aguiar, 470. CEP 05403 Sảo Paulo, SP. Brasil.

Dr. João Carlos Pereira Gomes. Faculdade de Medicina da USP - LIM 12. Ay. Dr. Amaldo, 455 - 2: andar - sala 116 . CEP 01246 Sảo Paulo, SP, Brasil.
} 
PEREIRA GOMES. J. C.: MAZIERI, N. A. de O.; GODOY. C. V. F. de \& ROCHA, A. dos S. - Legionella pneumophila associada a insuficiencia respiratória aguda. Primeiro isolamento no Brasil. Rev. Inst. Med. trop. S. Paulo, 31(6): 368376,1989

terminadas pelos mais variados agentes, desde vírus e fungos até bactérias de comprovação usualmente dificultosa. Dentre estes agentes, tem merecido atençāo dos investigadores bacté rias do gênero Legionella sp, tanto pelo caráter de surto epidêmico com que tem se apresentado, como por formas isoladas de pneumonias com quadros atípicos.

Em julho de 1976, durante a Convençāo da Legião Americana em um hotel de Philadelphia, EUA, houve um surto epidemico de uma forma de pneumonia rica em manifestaçōes sistêmicas e de alta mortalidade (19 óbitos em 182 casos), de etiologia desconhecida ${ }^{17}$. Meses depois, após intensas pesquisas nos C.D.C. - Centers for Disease Control - McDade e col. identificaram o agente responsável: um bacilo gram-negativo aeróbico, que foi denominado Legionella pneumophila ${ }^{30}$. Posteriormente multiplicaram-se os relatos de pneumonias por esta bactéria e outras bactérias do gênero Legionella ${ }^{12,13,21,22}$

Boa parte dos casos manifestaram-se através de surtos hospitalares, principalmente em pacientes cirúrgicos e imunodeprimidos ${ }^{21,22,32}$. Sabe-se hoje serem as legionelas responsáveis por um número significativo de pneumonias adquiridas em comunidade, mesmo em individuos previamente hígidos, podendo levar à insuficiência respiratória severa, por vezes letal ${ }^{19}$. 24, 25. 29. ${ }^{51}$. Apesar da gravidade que pode assumir, a evo lução das legioneloses para Sindrome do Desconforto Respiratório do Adulto (SDRA) tem sido pouco relatada ${ }^{5,21,40}$. Outras doenças podem ser causadas pelas legionelas, como a Febre de Pontiac, pericardite, infecção de fístula artério venosa, miocardite, abscesso hepático, pielone frite, abscesso cutâneo e inclusive endocardite em prótese valvar com hemocultura negativa para bactérias usuais ${ }^{15,21,22,43}$.

No Brasil, apenas quatro casos de pneumo nia por Legionella sp. foram relatados. BETH LEM \& GUSMĀO, em $1982^{2}$, comunicaram em congresso caso de pneumonia de má evolução que teve sorologia positiva para Legionella pneumophila realizada nos EUA, embora em apenas uma dosagem, sem referência de título Outros três casos, descritos por PEREIRA \& SILVA, em 1985, por PORTO et al., em $1986^{39}$ e por de PAULA et al., em $1986^{9}$ evoluíram bem com a introdução de eritromicina e tiveram diagnóstico sorológico firmado nos EUA por imunofluorescência indireta. Não houve, entre tanto, confirmaçāo pelo isolamento do agente nestes casos. VERONESI et al., em $1984^{44}$ realizaram inquérito sorológico em doadores de sangue e trabalhadores de Unidades de Terapia Intensiva (UTI) em 3 hospitais de Sâo Paulo. Dos 213 soros pesquisados pela técnica de imunofluorescência indireta apenas um apresentou título de anticorpos sugestivos (128) de contato prévio com Legionella pneumophila.

Nos últimos dois anos envidamos esforços para isolar estes microorganismos de material biológico de casos clínicos compatíveis, sem su cesso até a presente comunicaçāo. Apesar do emprego de metodologia bacteriológica específica para este agente fastidioso, problemas referentes à seleção adequada dos pacientes e à correta coleta de material certamente contribuíram para as dificuldades encontradas.

O presente trabalho refere-se à comunicaçāo de caso de insuficiência respiratória aguda com isolamento de Legionella pneumophila confirmado sorologicamente com aumento significativo de anticorpos específicos.

\section{DESCRIÇÃO DO CASO CLÍNICO}

L.C.P., 40 anos, masculino, branco, mecânico, procedente de São Paulo - SP, sem doenças prévias referidas, procurou o Pronto-Socorro do Hospital das Clínicas da Faculdade de Medicina da Universidade de São Paulo dia 25/01/88 com história de febre alta $\left(38,5-39^{\circ} \mathrm{C}\right)$, tosse com ex pectoraçāo escura em pequena quantidade, dor tipo pleurítica, sudorese, anorexia e mialgia há uma semana, evoluindo para dispnéia progressiva a esforços. Referiu ter sido medicado com penicilina nos últimos três dias sem melhora. Negava concomitância de cefaléia, hemoptises, náuseas, vômitos, diarréia e alterações urinárias. Tabagista de 40 cigarros por dia há 22 anos, eti lista social. Esteve em contato com água de represa 5 dias antes do início do quadro.

Ao exame físico de entrada apresentava-se em regular estado geral, com mucosas pouco co. radas, discretamente desidratado $(++/ 4)$, acianótico, sem edemas ou adenopatias. $P=120$; 
PEREIRA GOMES. J. C.: MAZIERI. N. A. de O.: GODOY. C. V. F. de \& ROCHA A dos S. - Iegionella pneumophila associada a insuficiencia respiratoria aguda. Primeiro isolamento no Brasil. Rev. Inst. Ned. trop. S. Paulo. 31 (bi) 368376.1989

$\mathrm{PA}=70 \times 50 \mathrm{mmHg} ; \mathrm{T}=38,5^{\circ} \mathrm{C} ;$ pulmòes com estertores crepitantes no terço médio do pulmão direito. Ao RX observava-se infiltrado alveolar e intersticial no campo médio do hemitórax direito (HTD), lobo superior e médio, e na base do hemitórax esquerdo (HTE) (Fig. 1). Uréia séri$\mathrm{ca}=69 \mathrm{mg} / \mathrm{dl}$; creatinina sérica $=2,3 \mathrm{~g} / \mathrm{dl}: \mathrm{Hb}$ $=11,8 \mathrm{~g} / \mathrm{dl}: \mathrm{Ht}=36 \% ; \mathrm{VCM}=75$; leucócitos $=9700 / \mathrm{mm}^{3}:$ bastonetes $=46 \%:$ segmentados $=49 \% ;$ Eosinófilos $=1 \% ;$ linfócitos $=3 \% ;$ monó citos $=1 \%$; plaquetas $=160.000 / \mathrm{mm}^{3}$. Urina $\mathbf{I}$ $=$ traços de proteinúria, 3 hemácias $/$ campo, 2 leucócitos/campo. Foi prescrito $1000 \mathrm{ml}$ de solu ção fisiológica em 1 hora e penicilina cristalina de 18.000.000 unidades EV/dia.

Evoluiu taquidispnéico, com agravamento do estado geral e hipoxemia severa refratária a quantidades crescentes de oxigenio, sendo entubado e submetido a respiração assistida com BIRD e transferido para UTI. Iniciou-se venti lação com Monagham, $\mathrm{FiO}_{2}$ ( Fração inspirada de $\mathrm{O}_{2}$ ) de 100\% e PEEP (Pressão Expiratória Final Positiva) de $14 \mathrm{~cm} \mathrm{de} \mathrm{H}_{2} \mathrm{O}$, sendo necessário dopamina para manter pressāo arterial. In trodu ziu-se clindamicina, amicacina e ceftriaxone.

No 3: dia o RX de tórax mostrou infil trado alveolar acometendo todo HTD e $2 / 3$ infe riores do HTE (Fig. 2). Gram de secreção tra-

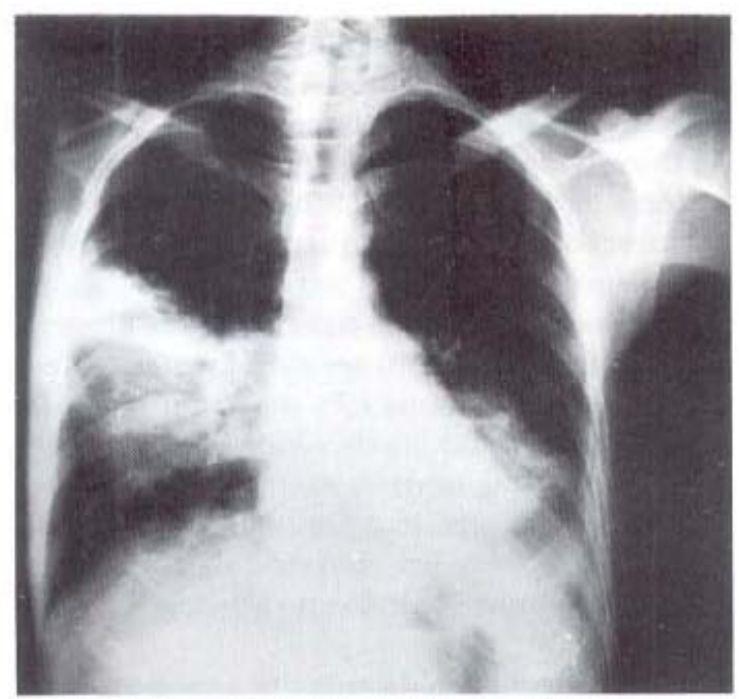

Fig. 1 - Radiografia do 1: dia de internaçào (Pronto-Socorro demonstrando infiltrado alveolar e intersticial no campo me dio do hemitorax direito (HTDi e base de hemitorax esquerdo (HTE).

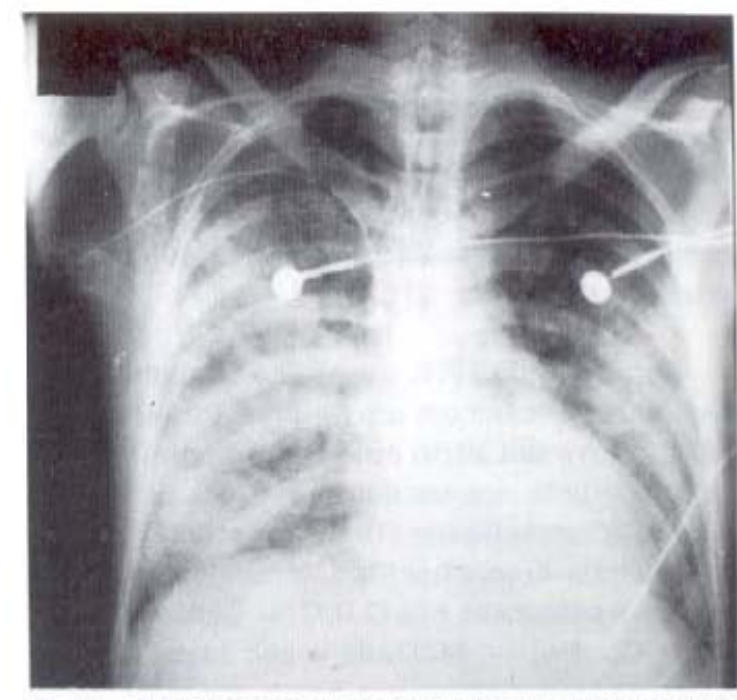

Fig. 2 - Radiografin do 3 dia de internaça (UTI) com infil trado alveolar acometendo todo HTD e 23 inferiores de HTE

queal: numerosos leucócitos e ausência de bac térias. Gasometria arterial com $\mathrm{FiO}_{2}=100 \%$ $\mathrm{pH}=7.48 ; \mathrm{pCO}_{2}=35.2 \mathrm{mmHg} ; \mathrm{pO}_{2}=101$ $\mathrm{mmHg}$ : Sat $=98,5 \% ; \mathrm{HCO}_{3}=26,7 \mathrm{meq}^{\prime} 1$. Dife rença alvéolo-arterial (DAa) $=512,8 \mathrm{mmHg}(\mathrm{nl}$ $=50-100) ; \mathrm{pO}_{2} \mathrm{FiO}_{2}=101 \mathrm{mmHg} / \%$; Shunt $=27,9(\mathrm{nl}<7 \%)$ : complacência $=18,4 \mathrm{ml} / \mathrm{cm}$ . $\mathrm{H}_{2} \mathrm{O}(\mathrm{nl}=50-100)$; leucócitos $=13.800 \mathrm{~mm}^{3}$.

Evoluiu com melhora gradativa do padrāo respiratório e do estado geral, estabilizando he modinâmica e redução da curva febril e leucoci tose. Como complicação desenvolveu infecçāo pulmonar secundária por Acinetobacter calcoaceticus, tratada com netilmicina. Foi extubado na terceira semana de internaçāo.

No 8: dia de internaçāo na UTI recebemos resultado de sorologia para Legionella, conside rado não conclusivo. Seis dias depois, a cultura revelou crescimento de bacilo Gram-negativo, identificado a posteriori como Legionella pneumophila sorogrupo 1. Apesar deste resultado. não se mudou o esquema antibioticoterápico de vido à melhora apresentada. As sorologias para micoplasma, virus respiratorios (influenza $\mathrm{A}, \mathrm{B}$ e $C$, parainfluenza, adenovirus, respiratório $\sin$ ciciall e anti-HIV foram negativas.

Recebeu alta hospitalar no 34 . dia de inter naça com gasometria arterial em ar ambiente de $\mathrm{pH}=7.45: \mathrm{pCO}_{2}=35.2 \mathrm{mmHg}: \mathrm{pO}_{2}=70$ 
PEREIRA GOMES, J. C.: MAZIERI, N. A. de O : GODOY, C. V. F. de \& ROCHA, A. dos S. - Legionella pneumophila associada a insuficiéncia respiratória aguda. Primeiro isolamento no Brasi]. Rev. Inst. Med. trop. S. Paulo, $31(6)$ : 368376.1989.

$\mathrm{mmHg} ; \mathrm{Sat}=94 \% ; \mathrm{HCO}_{3}=25,5 \mathrm{meq} / \mathrm{l}$. Radiolo gicamente vem apresentando lenta resoluçāo de imagem radiológica (ver Fig. $3-25$. dia, quando de alta da UTI e Fig. $4-2$ meses após início do quadro). Prova de função respiratória reali zada dia 04/03/88 mostrou diminuição global de volumes pulmonares compativel com restrição leve, ausência de obstruçāo, reduçāo acentuada $-19 \%-($ normal $>80 \%)$ de capacidade de difusão de monóxido de carbono.
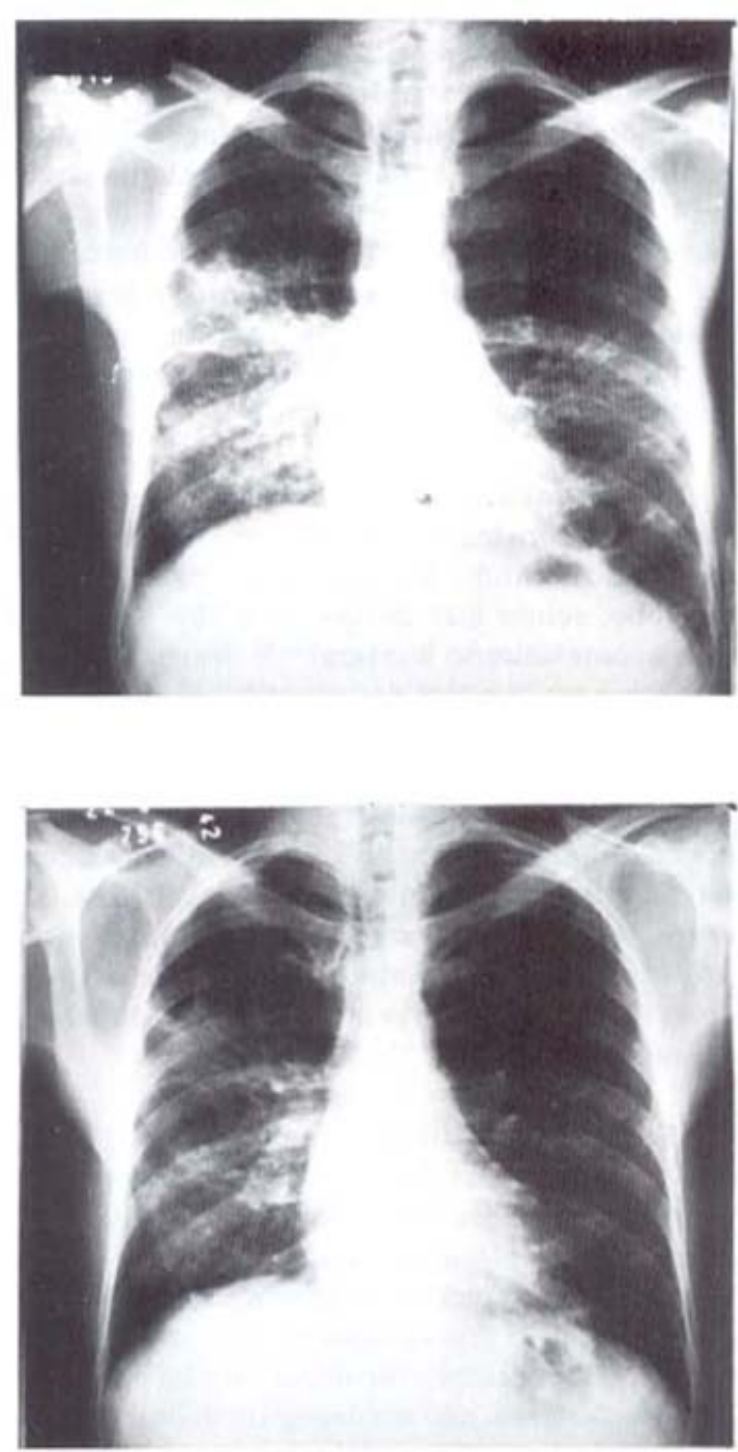

Fig. 3 e 4 - Radiografla do 25: dia de internaça ina alta da UTI e de 2 meses apos inieio do quadro demonstrando regres saio de imagens radiológicas.

\section{MÉTODOS}

Cultivo - A secreçāo traqueal foi semeada diretamente em placa de BCYE (Buffered Char coal Yeast Extract) e BCYE com antibióticos (ciclohexamida $80 \mu \mathrm{g} / \mathrm{ml}$, vancomicina $0,5 \mu \mathrm{g} / \mathrm{ml}$, colistina $16 \mu \mathrm{g} / \mathrm{ml}$, cefalotina $4 \mu \mathrm{g} / \mathrm{ml})^{11.14 .48}$. As semeaduras foram feitas em duplicatas, sendo uma com inóculo pesado e outra com normal, e incubadas à $35^{\circ} \mathrm{C}$, em ambiente úmido e atmos fera de $2,5 \%$ de $\mathrm{CO}_{2}$. A cultura foi examinada diariamente e a identificação foi feita por provas bioquímicas, reaçăo de imunofluorescência dire ta e aglutinaçāo em lâmina ${ }^{7.42 .45 .46 .47 .48 .}$.

Os reagentes para reaçāo de imunofluores. cência direta foram gentilmente cedidos pelo $\mathrm{C}$. D.C.. Utilizamos para o teste de aglutinação em lâmina imune-soro específico para Legionella pneumophila sorogrupo 1, produzido em coelho por nosso laboratório.

Sorologia - Foram colhidas 4 amostras de sangue respectivamente em 28/01/88, 08/02/88, $18 / 02 / 88$ e 01/03/88. A verificaçāo de anticorpos específicos para Legionella pneumophila foi feita pela técnica de imunofluorescência indireta ${ }^{7} .45 .46,48$.

O antígeno foi preparado segundo descrição na literatura ${ }^{7}$, com a cepa Legionella pneumophila sorogrupo 1 (Philadelphia 1) enviada pelo C.D.C. em 1985 e mantida em nosso laboratório. O conjugado (anti IgG, IgA e IgM-humano) marcado por fluoresceína foi o Fluorine "H" (Lab. Bio-Mérrieux), na diluiçāo de 1:200.

Os soros foram diluídos a partir de $1 / 16$ sendo que a diluição inicial foi feita em PBS 0,01 M; pH 7,6 com $3 \%$ de suspensão de saco vitelino de ovo embrionado (NYS) e diluiçāo seriada em PBS. As lâminas foram forradas com o antígeno específico, fixadas em acetona, incubadas com o soro do paciente durante 30 minutos a $37^{\circ} \mathrm{C}$ em câmara úmida e a seguir lavadas com PBS 0,01 M: pH 7,6 durante 10 minutos. Após adição do conjugado incubou-se durante $30 \mathrm{mi}$ nutos, em câmara úmida à $37^{\circ} \mathrm{C}$. Lavou-se novamente e fez-se a montagem com tampão glicerol pH 9,0 . 
PEREIRA GOMES. J. C.: MAZIERI. N. A. de O ; GODOY. C. V. F. de \& ROCHA, A. dos S. - Legionella pneumophila associada a insuficiēncia respiratória aguda. Primeiro isolamento no Brasil. Rev. Inst. Med. trop. S. Paulo, 31(6): 368376.1989

\section{RESULTADOS DA CULTURA E SOROLOGIA}

Cultura - Após 48 horas de incubação em meio BCYE houve crescimento de colônias sus peitas, onde verificou-se a presença de bacilos Gram-negativos de aproximadamente $0,5 \mu \mathrm{m}$ larg. por 1-2 $\mu \mathrm{m}$ de comprimento. Replaqueadas em BCYE sem cisteína, nāo houve crescimento, levando-nos às provas bioquímicas para gènero Legionella $\mathrm{sp}$. Com as reações de reduçâo de nitrato, urease e fermentação de glicose nega tivas e catalase fracamente positiva, seguiram se os testes presuntivos para espécie. Estes, compreendendo a liquefação de gelatina, hidrólise do hipurato e oxidase, foram todos positivos. A confirmação da espécie foi feita através da rea çào de imunofluorescência direta, mostrando-se positiva com intensidade de fluorescencia $4+$ para Legionella pneumophila sorogrupo 1 . O teste de aglutinação em lâmina foi fortemente positivo $(4+)$, sendo confirmado pela Dra. Hazel Wilkinson, C.D.C., EUA.

Sorologia - Os resultados obtidos na reaçāo de imunofluorescência indireta (Tabela 1) foram posteriormente confirmados pelo C.D.C

\section{TABELA 1}

Titulos sorológicos de anticorpos para Legionella pneumophila sorogrupo 1, pela reaçāo de Imunofluorescência Indireta

\begin{tabular}{lcc}
\hline Amostras & Data de coleta & IF 1 I \\
\hline 1. semana & $28 / 01 / 88$ & $1 / 128$ \\
2. semana & $08 / 12 / 88$ & $1 / 1024$ \\
4. Semana & $18 / 02 / 88$ & $1 / 4096$ \\
6. Semana & $01 / 03 / 88$ & $1 / 8192$ \\
\hline
\end{tabular}

\section{DISCUSSÃO}

Originalmente descrita na sua forma epidê mica, constatou-se com o tempo ser maior a incidência da Doença dos Legionários na forma de casos isolados ${ }^{18.19}$. E sugerido na literatura que $1 \%$ das pneumonias nos EUA $^{8}$ e cerca de 2 a $3 \%$ na Inglaterra, constituindo 6 a $15 \%$ das pneumonias adquiridas em comunidade ${ }^{27.32}$ sejam por Legionella $\mathrm{sp.} \mathrm{Variaçōes} \mathrm{sazonais,} \mathrm{anuais} \mathrm{e} \mathrm{re}$ gionais acarretam incidencias mais elevadas. Segundo estudo de BOUZA e col. ${ }^{4}, 6 \%$ das penu- monias diagnosticadas por seu serviço em Madrid, foram legioneloses: já um estudo prospectivo realizado em Pittsburg, EUA, encontrou cerca de $15 \%^{53}$. De 1980 a $1981,15 \%$ das pneumonias adquiridas em comunidade em Nothingham, Inglaterra, foi por esta etiologia. Passados dois anos a incidéncia caiu para $5 \%{ }^{27 .}{ }^{51}$.

Como antecedentes epidemiológicos associados temos o sexo, a idade, o tabagismo e o contato com água no verão. Cerca de dois terços dos casos ocorrem em homens, a maioria com mais de 30 anos, sendo a idade média de 50 a $56 \operatorname{anos}^{13.19,21}$. A incidência em tabagistas é significativa nos casos de comunidade, embora nāo difira daquela observada por pneumococo ${ }^{13,52}$. As legionelas já foram isoladas em lagos, encanamentos, sistema de ar condicionado e água potável $^{12}$. Vários estudos encontraram pico de incidência nos meses de verão e início de outono ${ }^{13}$. 19. 21. O intervalo de cinco dias entre o contato deste paciente com a água de represa e o início de sintomatologia é compativel com o periodo de incubação destas bactérias ${ }^{12.17}$.

Nos primeiros dias de doença, as pneumonias por legionelas demonstram mais comumen te ao raio $\mathrm{X}$, infiltrado alveolar localizado $\mathrm{em}$ um lobo, sendo que destes, 40 a $50 \%$ evoluem com acometimento bilateral ${ }^{19,23}$. Derrame pleural ocorre em 16 a $35 \%$ dos $\operatorname{casos}^{19,23,28}$. A Doença dos Legionários caracteriza-se por deterioração de imagem no início do tratamento, independente de melhora clínica ${ }^{21}$ e resolução mais tardia do quadro radiológico ${ }^{28}$. O paciente em questāo foi internado com sete dias de história, já apresentando infiltrado alveolar bilateral que posteriormente acometeu difusamente os pulmōes com agravamento do quadro de insuficiência respiratória.

Embora apresentando com freqüencia algu mas características, tais como tosse seca ou pou co produtiva, febre alta, confusāo mental, hipo natremia, hipoalbuminemia, progressāo de imagem radiológica pulmonar apesar de melhora clínica, e em casos graves hipotensão, insuficiência renal, leucopenia, alteraçōes de funçāo hepática e hipofosfatemia, não se conseguiu definir alteraçôes clínico-radiológico-laboratoriais que especificamente distinguissem a Doença dos Legio nários de outros tipos de pneumonias ${ }^{18}$. 19. 21.24. 
PERFIRA GOMES, J. C.: MAZIERI. N. A de O: GODOY, C. V. F. de \& ROCHA. A. dos S -- Legionella pneumophila associada a insuficiencia respiratória aguda. Primeiro isolamento no Brasil. Rev. Inst. Med. trop. S. Paulo, 3 ( $(6)$ : 368376,1989

51. 52.53. A bacterioscopia negativa pelo GRAM, a falta de resposta a beta-lactámios e aminoglicosídeos, associadas às caracteristicas acima referidas, sugerem a etiologia por Legionella $\mathrm{sp.}$ em pacientes com pneumonia ${ }^{12}$. Nosso paciente, já no pronto-socorro, apresentava indicios clínicos suficientes para justificar pesquisa de Legionella sp. Nesta ocasião contudo, nảo se levantou tal suspeita, posteriormente aventada diante da evolução clínica.

A Doença dos Legionários pode evoluir para formas graves, com insuficiência respiratória que necessite de cuidados intensivos e inclusive encaminhar-se para choque e insuficiencia de múltiplos órgāos ${ }^{21.22}$. O pior prognóstico relaciona-se com a presença de doença de base e o retardo na instituiçào de terapéutica apropriada ${ }^{5.21}$. A evoluça para SDRA entretanto é pouco encontrada ${ }^{5}$ 21. 40. Esta sindrome é entidade resul tante da agressão aguda à membrana al véolo-capilar por fatores etiológicos diversos. resultando em aumento de permeabilidade dos vasos, edema pulmonar, fibrose, infiltrados pulmonares difusos ao RX e importantes alteraçoes funcionais, que culminam como $\mathrm{PaO}_{2}$ menor que $50 \mathrm{mmHg}$ em vigência de $\mathrm{FiO}_{2}$ maior que 0,6. complacéncia respiratória total menor que $50 \mathrm{ml} / \mathrm{cm} \mathrm{H} \mathrm{H}_{2} \mathrm{O}$, shunt e espaço morto aumentados ${ }^{36,38}$. Embora nào tenhamos medidas de pressão capilar pulmonar, nem biópsia pulmonar, a instalação de hipoxemia severa refratária a elevados $\mathrm{FiO}_{2}$ e o aparecimento de infiltrados difusos bilaterais ao RX em doente sem cardiopatia prévia que nảo desenvolveu insuficiência cardiaca durante e após o quadro nos sugere clinicamente tratar se de caso de SDRA ${ }^{33.36}$

A instituição de medidas de suporte foi fundamental na estabilizaçāo do quadro inicial e na evolução posterior. A utilizaçāo de aparelho ciclado a volume possibilitou maior conforto e melhor ventilaçáo. Mesmo necessitando inicialmente de mais droga vasoativa para manter estado hemodinàmico, a introduçāo de PEEP foi determinante na melhora gasométrica e possibilitou a reduçāo gradativa de $\mathrm{FiO}_{2}$.

Como nāo tínhamos o diagnóstico etioló gico na entrada da UTI, optamos por um esque ma de amplo espectro com clindamicina, amica cina e ceftriaxone. Apesar de termos suspeitado de Legionela sp., a não constatação de sua ocor rência clínica em Sāo Paulo até então, e a estabi lizaçāo subseqüente do quadro levou-nos a nảo introduzir eritromicina. Quando recebemos o re sultado laboratorial definitivo, o paciente já es tava em recuperaçāo. Apesar dos antibióticos utilizados serem descritos como menos eficazes "in vivo" e "in vitro" contra Legionella sp. ${ }^{17 .}{ }^{19}$ ${ }^{21}$, provavelmente contribuíram para redução da curva febril e leucocitose observada nos primei ros dias além do desenvolvimento pelo paciente de imunidade específica. Há possibilidade de ha ver sinergismo destes antimicrobianos para a Legionella sp.. Contudo, de acordo com a litera tura ${ }^{10 .}{ }^{26.50}$, não há até o presente, metodologia "in vitro" padronizada para tal averigüaçāo.

Embora apresentando dispnéia a esforços após a alta e seqüela às provas de função pulmo nar, as possibilidades do paciente evoluir para recuperaçāo praticamente total sāo boas. Dos sobreviventes à SDRA mais de $70 \%$ recuperam se sem seqüelas funcionais após período de 6 a 12 meses, restando $19 \%$ com padrão obstrutivo e $21 \%$ com capacidade difusional menor que $80 \%$ 1. 20. 41 . Radiologicamente $11,1 \%$ evoluem com infiltrado intersticial e 7,4\% com hiperinsuflaçāo pulmonar. A maioria $(80 \%)$ tem $\mathrm{RX}$ nor malizado no seguimento. A Doença dos Legioná rios, mesmo sem preencher os critérios para SDRA, pode por si só evoluir com fibrose pulmonar e persistencia de anormalidade funcionais principalmente reduçäo de capacidade difusio nal. Certos pacientes chegam a caminhar para insuficiência respiratória e óbito ${ }^{6 .}{ }^{24}$. Em casos com SDRA e legionelose, a recuperação quase integral também pode ocorrer, deixando míni mas seqüelas ${ }^{40}$. Nosso paciente estava apresen tando regressào gradativa de lesōes.

$\mathrm{O}$ isolamento de Legionella pneumophila sorogrupo 1, bem como a confirmaçào sorológica foi possivel pelo emprego e persis tência na meto dologia específica e pela coleta precoce, correta e seqüencial de material biológico do paciente. A dificuldade de se obter controles adequados levou-nos inicialmente a um excesso de rigor na interpretação dos resultados sorológicos, confe rindo à amostra de $18 / 02 / 88$ o título 2048 ao invés de 4096. 
PEREIRA GOMES. J. C.: MAZIERI. N. A. de O.; GODOY. C. V. F. de \& ROCHA. A. dos S. - Legionella pneumophila associada a insuficiência respiratória aguda. Primeiro isolamento no Brasil. Rev. Inst. Med. trop. S. Paulo, $31(6)$ : 368376.1989

O baixo título de anticorpos da primeira amostra, nảo permitiu a valorizaçảo segura do diagnóstico laboratorial. Somente com a soro conversão obtida nas amostras de sangue subse qüentes, acrescida do isolamento e identificação do microorganismo, pudemos afirmar o diagnóstico etiológico definitivo. A confirmação poste rior dos títulos de anticorpos pelo C.D.C. nos assegurou serem fidedignos a especificidade $\mathrm{e}$ reprodutibilidade da reação de IF 11 .

\section{CONCLUSŌES}

O isolamento da Legionella pneumophila sorogrupo 1 de secreção traqueal de paciente com pneumonia comprova de maneira definitiva a presença desta bactéria no Brasil como agente patogênico, associado à pneumonia com insufi ciência respiratória aguda.

O conjunto das medidas de suporte (venti lação ciclada a volume, PEEP, monitorizaçāo em UTI) foi fundamental na estabilização do quadro clínico e na recuperação do doente.

Destacamos ainda a importância de lem brarmos de Legionella sp. ao fazermos o diag nóstico diferencial de pneumonias, bem como a necessidade de continuar a pesquisa desta etiologia utilizando metodologia laboratorial es pecifica.

\section{SUMMARY}

Legionella pneumophila associated to acute respiratory insufficiency. First isolation in Brazil.

Isolation of Legionella pneumophila serogroup 1 with serological evidence of present in fection is reported from a 40 year-old male with serious respiratory infection which developed in to acute respiratory failure. It was characterized by severe hypoxemia resistant to high inspired oxygen concentrations and radiographycally by diffuse infiltrates in both lungs suggesting the clinical aspect of ARDS. Following the introduc tion of clindamycin, amikacin, ceftriaxone, volu me-cycled ventilator and positive end expirato ry pressure ( $\mathrm{PEEP}$ ) of $14 \mathrm{~cm} \mathrm{H}_{2} \mathrm{O}$, stabilization of clinical conditions and gradual recovery were achieved.
Suspecting of legionellosis, blood and tracheal secretions specimens were collected for specific laboratory research. From tracheal se cretion cultivated in BCYE medium, gram-ne gative bacilli were isolated and identified as Le gionella pneumophila serogroup 1 through cul. tural and biochemical characteristics and direct immunofluorescence and slide agglutination tests. Serology (IF A) with blood samples collec ting during the $1^{\text {st }}, 3^{\text {rd }}, 4^{\text {th }}$ and $6^{\text {th }}$ weeks of illness demonstrated antibody titers to the isolated $\mathrm{mi}$ croorganism of $128,1024,4096$ and 8192 , respectively. Definitive results were obtained during the patient's recovery.

The authors emphasize: a) the demonstra tion of the presence of Legionella sp. as a patho genic agent in Brazil; b) the importance of supportive care in the clinical outcome; c) the need of remembering this pathogen while making dif ferential diagnosis of pneumonias and of conti nuing to pursue this etiology with specific laboratory methodology

\section{AGRADECIMEN'TOS}

Os autores agradecem: ao Prof. Dr. Ricardo Veronesi, Prof. Titular da Clínica de Moléstias Infecciosas e Parasitárias da FMUSP que, como Chefe do LIM/54 - Bacteriologia HC-FMUSP, nos incentivou ao estudo de Legionelose; à Dra. Hazel Wilkinson, Chefe do Laboratório de Imu nologia de Doenças Respiratórias Bacterianas, C.D.C., Atlanta, G.A., pelo auxílio no envio de amostras padróes para implantaçāo do Laboratório de Legionella e pelas confirmaçóes realizadas na identificaçāo e sorologia neste trabalho.

\section{REFERENCIAS BIBLIOGRAFICAS}

1. ALBERTS, W. M.; PRIEST, G. R. \& MOSER. K. M. The outlook for survivors of ARDS. Chest, 84: $272-274$. 1983.

2. Bethlem, N. \& GUSMÃo, J. M. - Descrição de um caso de pneumonia por Legionella pneumophila. J. Pneu. mol., 8 (Supl): 207, 1982

3. BOLIN, R. W. \& PIERSON, D. J. - Ventilatory manage ment in acute lung injury. Crit. Care Clin., 2: 585 589, 1986

4. BOUZA, E. \& RODRIGUEZ CREIXEMS, M. - Legio nnaires Disease in Spain. In: THORNSBERRY, C.: BA LOWS. A.: FEELEY, J. C. \& JAKUBOWSKI. W.. ed. LE. 
PEREIRA GOMES, J. C.: MAZIERI. N. A. de O.: GODOY. C. V. F. de \& ROCHA, A. dos S. - Legionella pneumophila associada a insuficiencia respiratoria aguda. Primeiro isolamento no Brasil. Rev. Inst. Med. trop. S. Paulo, 31(6): 368-376. 1989

GIONELLA. Proceedings of the $2^{\text {rd }}$ International Sympo sium. Washington, American Society for Microbiology. 1984. p. 15-17.

5. CARETTE, M. F.: HOUACINE, S.: DOURNON, E.: BURE, A.; MAILLET, J. \& MAYAUD, C. - Détresse respiratoire aiguë compliquant la maladie des légionnaires. Presse méd., 12: 102-103, 1983

6. CHASTRE, J.; RAGHU, G.; SOLER, P.: BRUN, P.: BAS SET, F. \& GILBERT, C. - Pulmonary fibrosis following pneumonia due to acute Legionnaires' disease. Chest, 91: $57-62,1987$

7 CHERRY, W B \& McKINNEY, R M - Detection of Legionnaires' disease bacteria in clinical specimens by direct immunofluorescence. In: JONES, G. L. \& HERBERT, G. A., ed. - Legionnaires': the bacterium and methodology. Atlanta, Georgia. Center for Disease Control, 1979. p. 91-103

8. CONNOLLY, C. K. \& HARRISON, B. - Treatment of pneu monia (letter). Brit. med. J., 290: 1586, 1985

9. DE PAULA, A. B.; CALAZANS, C. A. C.; VILELA, A. L. \& FERREIRA, E. - Doenca dos Legionários em Ita tinga, M. G. In: CONGRESSO BRASILEIRO DE INFECTOLOGIA. 3, Petrópolis RJ, 1986. Anais. p. 79

10. DOWLING, J. N.: WEYANT, R. S. \& PASCUALE, A. W. - Bactericidal activity of antibiotic against Legionella micdadei, (Pittsburgh pneumonia agent). Antimicrob. Agents Chemoter., 22: 272-276, 1982.

11. EDELSTEIN, P. H. - Culture diagnosis of Legionella in fections. Zbl. Bakt. Hyg. I Abt. Orig. A, 255: 96-101, 1983

12. EDELSTEIN, M. D. \& MEYER, R. D. - Legionnaires' Disease: a review. Chest, 85: 114-120, 1984

13. ENGLAND III, A C : FRASER, D W : PLIKAYTIS, $B$ D.: TSAI, T. F.: STORCH, G. \& BROOME, C. V. - Sporadic legionellosis in the United States: the first thousand cases. Ann. intern. Med., 94: 164-170, 1981

14. FEELEY J C. GIBSON R. J : GORMAN G W : LANG FORD, N.C.; RASHEED.J. K.: MACKEL, D.C. \& BAINE, W. B. - Charcoal - yeast extract agar: primary isolation medium for Legionella pneumophila. J. elin. Microbiol., 10: $437-441,1979$

15. FINEGOLD, S. M. - Legionnaires' disease - still with us. New Engl. J. Med., 318: 571-572, 1988

16. FOY, H. M.; HAYES, P. S.; COONEY, M. K.; BROOME, C. V.: ALLAN, I. \& 'TOBE, R. - Legionnaires' disease in a prepaid medical-care group in Seattle 1963-75. Lancet, 1: $767 \cdot 770,1979$

17. FRASER, D. W.: TSAI, T. R.; ORENSTEIN, W : PARKIN W. E.; BEECHAM, H. J ; SHARRAR, R. G.; HARRIS. J.; MALLISON, G. F.; MARTIN, S. M ; MCDADE. J. E.; SHE PARD, C. C. \& BRACHMAN, P. S. - Legionnaires' disease: description of an epidemic of pneumonia. New Engl. J. Med., 297: 1187-1197, 1977.
18 FRIIS-MOLLER A : RECHNITZER C : BLACK F T COLLINS, M. T.; LIND, K. \& AALUND, O. - Prevalence of Legionnaires' disease in pneumonia patients adnitted to a Danish Department of Infectious Disease. Scand. J. infect. Dis., 18: 321-328, 1986.

19. HELMS, C. M.: VINER, I. P.: WEISENBURGER, D D CHIU, L. C.: RENNER, E. D. \& JOHNSON, W - Sporadic Legionnaires' disease: clinical observations on 87 nosoco mial and comunity acquired cases. Amer. J. med. Sci. 288: $2-12,1984$

20. INGBAR. D. H. \& MATTHAY, R. A. - Pulmonary secuelae and lung repair in survivors of the adult respiratory distress syndrome. Crit. Care Clin., 2: 629 665, 1986

21. KIRBY, B. D.; SNYDER, K. M.; MEYER, R. D. \& FINE GOLD S. M. - Legionnaires' disease: report of sixty five nosocomially acquired cases and review of the literature. Medicine, 59: 188.205, 1980

22. KORVICK, J. A. \& YU, V. L. - Legionnaires' disease An emerging surgical problem. Ann. thorac. Surg., 43: 341-346, 1987.

23. KROBOTH, F. I.; YU, V. L.; REDDY, S. C. \& YU, A. C - Clinicoradiographic correlation with the extent of Le gionnaire disease. Amer. J. Roentgenol, 141: 263-268, 1983

24. LATTIMER, G. L,; RHODES III, L. V.: SALVENTI, J S.; GALGON, J. P.; STONEBRAKER, V.; BOLEY, S. \& HAAS, G. - The Philadelnhia epidemic of Legionnaires disease: clinical, pulmonary, and sorologic findings two years later. Ann. intern. Med., 90: 522-526, 1979

25. LEHOT, J. J.: XUAN, B. B.; MEUNIER, J.; THOMAS L.; BLANC, P. L.; ROBERT, D. \& BORNSTEIN, N. Maladie des légionnaires cinq cas de détresse respiratoire aiguë. Nouv. Presse méd., 11: 865, 1982

26 IENNETTE H E BALOUS A - HAUSLER W J \& SHA DOMY, H. J. - Manual of clinical microbiology. Fourth Edition. Washington, D. C. American Society for Microbio logy, 1985. Chapter 31. D. 380 .

27. MeFARLANE, J. T.; WARD, M. J.; FINCH, R. G. \& MA CRAE, A. D. - Hospital study of adult community acquired pneumonia. Lancet, 2: 255-258, 1982.

28. MCFARLANE, J. T.; MILLER, A. C.: RODERICK SMITH W. H. MORRIS, A. H. \& ROSE, D. H. - Comparative radiographic features of community acquired Legionnai res' disease, pneumococcal pneumonia mycoplasma pneumonia, and psittacosis. Thorax, 39: 28-33, 1984

29. MAYAUD, C.; CARETTE, M. F.; DOURNON. E.; BURE. A.; FRANÇOIS, T. \& AKOUN, G. - Clinical features and prognosis of severe pneumonia caused by Legionella pneumophila. In: THORNSBERRY, C.; BALOWS, A. FEELEY, J. C. \& JAKUBOWSKI, W., ed. LEGIONELLA. Proceedings of the $2^{\text {nd }}$ International Symposium. Wa shington. American Society for Microbiology, 1984. p 1112 .

30. MCDADE. J. E.: SHEPARD. C. C.: FRASER, D. W.; TSAI T. R.: REDUS, M. A.\& DOWDLE. W. R. - Legionnaires' 
PEREIRA GOMES. J. C.: MAZIERI. N. A. de O.: GODOY, C. V. F. de \& ROCHA. A. dos S. - Legionella pneumophila associada a insuficiencia respiratória aguda. Primeiro isolamento no Brasil. Rev. Inst. Med. trop. S. Paulo, 31(6): 368376.1989

disease: isolation of a bacterium and demonstration of its role in other respiratory disease. New Engl. J. Med. 297: 1197-1203. 1977 .

31. MEYER, R. D. - Legionella infections: a review of five years of research. Rev. infect. Dis. 5: 258-278, 1983.

32. MEYER, R. D. - Legionnaires disease: aspects of nosoco mial infection. Amer. J. Med., 76: 657-663, 1984

33. MEYRICK, B. - Pathology of the adult respiratory distress syndrome. Crit. Care Clin., 2: 429-453, 1986

34. MUDER, R. R.; YU, V. L. \& WOO, A. H. - Mode of trans mission of Legionella pneumophila. Arch. intern. Med. 146: $1607-1612,1986$

35. NIEDERMAN. M. S. \& FEIN. A. M. -- The interation of infection and the Adult Respiratory Distress Syndrome Crit. Care Clin., 2: 471-495, 1986

36. PEPE P. E. - The clinical entity of Adult Respiratory Distress Syndrome: definition, prediction, and prognosis. Crit. Care Clin., 2: 377 403, 1986.

37. PEREIRA e SILVA, J. L. - Doença dos legionarios: relato do primeiro caso no Brasil. J. Pneumol., 1111: 2630.1985.

38. PETTY. T. L. \& FOWLER, A. A. - Another look at ARDS. Chest, 82: 98104,1982

39. PORTO, N. S.; PALOMBINI. B. C.; PETRILLO. V. F. \& ALVES, M. R. A. - Pneumonia por Legionella pneumophila - Relato do segundo caso brasileiro. Rev. Inst. Med. trop. S. Paulo, 28: 368-370, 1986

40. SHAW, R. A.; WHITCOMB, M. E. \& SCHOUFELD, S. A - Pulmonary function after Adult Respiratory Distress Syndrome associated with Legionnaires' disease pneumo nia. Arch. intern. med., 141: 741-742, 1981

41. SIMPSON, D. L.: GOODMAN, M.: SPECTOR, S. L. \& PETTY. T. L. - Long term follow up and bronchial reacti vity testing in survivors of the adult respiratory distress syndrome. A mer. Rev. resp. Dis., 117: 449-454, 1978

42. THACKER, W. L.: PLIKAYTIS. B. B. \& WILKINSON H. M. - Identification of 22 Legionella species and 33 sero groups with the slide aglutination test. J. clin. Microbiol. 21: 779-782, 1985

43. TOMPKINS, L. S.; ROESSLER. B. J.: REDD. S. S.: MAR KOWITZ, L. E. \& COHEN, M. L. - Legionella prosthe tic-valve endocarditis. New Engl. J. Med., 318: 530.535 1988.
44 VERONESI, R: BARBOSA, S. F C : COSCINA, A L \& LIMA, A. C. C. - Legionelose no Brasil. Inquérito soroló gico entre doadores de sangue e trabalhadores em unidades de terapia intensiva de trés hospitais de Sảo Paulo. Rev. Hosp. Clín. Fac. Med. S. Paulo, 39: 257-259, 1984

45. WILKINSON, H. W.; FRASHY, C. E.; FIKES, B. J.: CRU CE, D. D. \& YEALY, L. P. - Measure of immunoglcbulin G - M - and A specific titers against Legionella pneumophila and inhibition of titers against non-specific, gram negative bacterial antigens in the indirect immunofluorescence test for legionellosis. J. clin. Microbiol., 10; $685-689,1979$

46. WILKINSON, H. W.; FIKES, B. J. \& CRUCE, D. D. Indirect immunofluorescence test for serodiagnosis of le gionnaires' disease: evidence for serogroup diversity of Legionnaires' disease bacterial antigens and for multiple specificity of human antibodies. J. clin. Microbiol., 9: $379-383,1979$.

47. WILKINSON, H. W. \& BRENNER, B. J. - Detection of cell-associated or soluble antigens of Legionella pneumophila serogroups 1 to 6 , Legionella bozemanii, Legionella dumoffii, Legionella gormanii, and Legionella micdadei by Staphylococcal coaglutination test. J. clin. Microbiol., 14: $322-325,1981$

48. WILKINSON, H. W. - Hospital - Laboratory diagnosis of Legionella infections. Atlanta. Georgia, Centers for Di sease Control. 1987, p. 1.42.

49. WINN Jr, W. C. \& MYEROWITZ, R. L. - The pathology of the Legionella pneumonias. A review of 74 cases and the literature. Hum. Path., 12: 401-422, 1981.

50. WINN Jr, W. C. - Legionnaires' disease: historical perspective. Clin. Microbiol., 1: 60-81, 1988.

51. WOODHEAD, M. A. \& McFARLANE, J. T. - Legionnai res' disease: a review of 79 community acquired cases in Nottingham. Thorax, 41: 635-640, 1986.

52. WOODHEAD, M. A. \& MacFARLANE, J. T. - Compa rative clinical and laboratory features of Legionella with Pneumococcal and Mycoplasma pneumonias. Brit. J. Dis. Chest, 81:133-139,1987.

53. YU, V. L.; KROBOTH, F. J ; SHONNARD, J.; BROWN A.; MCDEARMAN, S. \& MAGNUSSEN, M. - Legionnaires' disease: new perspective from a prospective pneumonia study. Amer. J. Med., 73: 357-361, 1982.

Recebido para publicação em 18/4/1989. 